\title{
Intravenous Immunoglobulin in Neonates: Current Perspective
}

\author{
Rabindran', Gedam DS ${ }^{2}$ \\ ${ }^{1}$ Dr. Rabindran, Consultant, Neonatologist, Billroth Hospital, Chennai, India, ${ }^{2}$ Dr. D Sharad Gedam, Professor of \\ Pediatrics, L N Medical college, Bhopal, MP, India.
}

Address for Correspondence: Dr Rabindran, E mail: rabindranindia@yahoo.co.in

\begin{abstract}
IVIG is being used off-label in newborns for sepsis prophylaxis, treatment of neonatal alloimmune diseases such as HDN \& NAIT.Though earlier studies supported IVIG prophylaxis in neonatal sepsis prevention, latest INIS Trial showed that IVIG is not recommended to prevent neonatal sepsis. Use in treatment of sepsis remains controversial. Cochrane systematic review suggested a beneficial effect on mortality. Significant reduction in mortality occurred with addition of IgM-enriched IVIG. Nowadays IVIG is being increasingly used in Hemolytic Disorders mainly blood group incompatibility. It has been found to reduce multiple exchange transfusions, length of hospital stay \& duration of phototherapy. Possible side effects include fever, allergic reactions, hypoglycaemia, hypotension, haemolysis, fluid overload \& anaphylaxis. Pending FDA approval, prompt \& judicious administration of IVIG with close monitoring for any adverse events is mandatory.
\end{abstract}

Key words: Intravenous Immunoglobulin, Hemorrhagic disease of newborn, sepsis prophylaxis.

\section{Introduction}

IVIG is concentrated, purified solution ofimmunoglobulins derived from pooled donor plasma. Inspite of approval for use in children, there are no FDA approval for newborns [1]. However it is being used off-label in newborns for sepsis prophylaxis particularly in LBW infants \& treatment of neonatal alloimmune diseases such as HDN\&NAIT. Recently IVIG has been used in parvovirus B19 infection, hemochromatosis \& neonatal Kawasaki disease.

Mechanism of action: The proposed mechanism of action include.

1. Antibodyspecific immunity-Providing opsonic antibody against pathogens enhancing phagocytosis \& neutrophil mediated killing of bacteria $[2,3]$.

2. Improving B cell function \& complement system [4, $5,6]$.

3. Blocking Fc receptor \& thereby blocking binding of antibody to antigen [7].

4. Binding to fragment crystallizable receptors on phagocytes, NK cells \& Reticulo-endothelial cells.

Manuscript received: $30^{\mathrm{TH}}$ Dec 2015

Reviewed: $11^{\text {th }}$ Jan 2016

Author Corrected; $21^{\text {th }}$ Jan 2016

Accepted for Publication: $30^{\text {th }}$ Jan 2016
5. Neutralizing toxins, immunomodulating $\mathrm{T}$ cells \& macrophages.

6. Down-regulation of inflammatory cytokines [4, 8].

7. Improving neutrophil chemiluminescence [2].

8. Improving Neutropenia byenhancing the release of stored neutrophils [9].

Prophylaxis in sepsis: TransplacentalIgG transfer begins at 8-10 weeks of age \& accelerates after 32 weeks gestation. So preterm infants have decreased immunoglobulin concentrations \& also have an increased susceptibility for sepsis [10]. They respond to a harmful insult with an attenuated innate immune response. This protective response to prevent organ damage in utero becomes harmful after birth [11]. Moreover immunoglobulin levels decline further after birth.This relative $\operatorname{IgG}$ deficiency has upto 86-fold increased rate of sepsis in newborns with birth weight of 600-900 grams compared with those weighing more than 2,500 grams [11]. Earlier many studies [12, 13, 14] found that IVIG prophylaxis significantly reduced the number of infective episodes. Howeverin a systematic review of 19 trials involving $>5000$ preterm / LBW infants, prophylactic IVIG reduced the rate of late-onset infection by $3 \%$ with no significant reduction in mortality [15].Other studies found $[16,17,18,19]$ found 
no effect of IVIG in neonatal sepsis prevention. According to latest INIS Trial, IVIG is not recommended to prevent neonatal sepsis (grade A recommendation, level Ia evidence) [20].

Adjunctive therapy in sepsis: IVIG has been used for the treatment of neonatal sepsis since 1980's, but its usage remains controversial $[15,21,22]$. Three Cochrane systematic reviews, including nearly 6000 patients, suggested positive effects on mortality with use of IVIG in proven or suspected sepsis of preterm newborn $[15,23]$. Cochrane systematic review \& meta-analysis of IVIG used for treating sepsis in neonates suggested a beneficial effect of IVIG on all cause mortality (RR 0.64) [24]. Other Studies have shown an increased mortality in septic neonates given antibiotics without IVIG, compared to thosegiven antibiotics plus IVIG $[25,26]$. A systematic review of 7 trials of adjunctive therapy of IVIG involving 338 newborns of any gestational age that had suspected/ proven sepsis showed no difference in mortality [24].

IgM has the capacity to induce pronounced activation of complement system. IgM activates 100-400 fold more complement than $\mathrm{IgG} \&$ is a more effective killer of bacteria. Opsonisation by $\operatorname{IgM}$ is also 1000 -fold greater than IgG [27].

It is more potent against the septic process, possibly because of its size, which permits a more efficient inhibition of the lipopolysaccharide core on the bacterial surface during neonatal sepsis. Various systematic reviews on the use of polyclonal IgMenriched IVIG in severe sepsis in neonates found significant reduction in mortality with addition of IgMenriched IVIG [15, 28, 29, 30,31]. Two clinical trials [32,33] \& a Metaanalysis [28] showed that patients with gram-negative sepsis had a significantly lower rate of mortality after IgM-enriched IVIG compared with control groups.However another study evaluating use of IgM-enriched Ig for the treatment of sepsis in 44 preterms showed that mortality in control group $(37.5 \%) \&$ immunotherapy group $(30.0 \%)$ were not significantly different. A multicentric placebo controlled trial showed significant decrease in mortality in first 7 days, while survival at 56 days had not improved significantly [25].

Cochrane Database update showed that the use of IgMenriched IVIG is still insufficient to support a conclusion ofbenefit on neonatal sepsis [24]. In 2011the INIS Study showed from a double-blind, randomized, placebo controlled trial in 3493 infants diagnosed with suspected or culture-proven sepsis that IVIG did not change the primary outcome of mortality or major disability at 2 years of age [20].

Hemorrhagicdisease of the newborn: Blood group incompatibility is reported to occur in $15 \%-25 \%$ of pregnancies [34]. Neonatal IVIGuseforhemolyticanemia was first reported in 1987 in the treatment oflateanemia due to rhesus E incompatibility [35]. It was then used in other forms of Hemolytic Disorders mainly blood group incompatibility [36, 37, 38,39]. Most studies have compared IVIG with the need for exchange transfusion and almost all have found a reduction (Grade A) [31, $36,37,38,40,41,42]$. There is also a significant reduction in the number requiring multiple exchange transfusions (RR 0.22), length of hospital stay (WMD $-1.06)$ \& duration of phototherapy (WMD -0.87 ). The NNT to prevent one exchange transfusion is very low at 2.7 [42]. AAP recommends IVIG as an adjunct therapy in the management on HDN [37]. AAP 2004 guidelines recommend administration of IVIG in isoimmune haemolytic disease if the TSB is risingat 8-17 micromol/L/hour despite intensive phototherapyor the TSB level is within $34-51 \mu \mathrm{mol} / \mathrm{l}(2-3 \mathrm{mg} / \mathrm{dl})$ of the exchange level. IVIG also decreases the risk of neurological impairment as it decreases time in the high-risk zones on the Bhutaninomogram [36]. Multiple dose IVIG resulted in a greater percentage reduction in the need for exchange transfusion [43].

The NHS report suggests IVIG use in selected cases of HDN with worsening hyperbilirubinaemia (grade B recommendation, level III evidence) [44] whereas a meta-analysis of RCTs showed grade A, level 1a evidence [37,39]. However, no consistent effect of IVIg on duration of phototherapy has been observed [38]. A study reported considering IVIG in Zone 4 for preterm infants \& Zone 5 for term infants [45].

ABO hemolytic disease: Useof IVIG in ABO hemolytic disease has been reported in a few studies $[46,47]$. It reduces the need for exchange transfusion without producing immediate adverse effects in $\mathrm{ABO}$ hemolytic disease with positive direct Coomb's test.

Alloimmunethrombocytopenia: In the neonatal period, IVIG has been used for the treatment of alloimmunethrombocytopenia [48, 49]. It is recommended for NAIT if other treatments fail (grade $\mathrm{C}$ recommendation, level III evidence) \& is effective in $75 \%$ of cases. High-dose IVIG (400 mg/kg day over 5 
days) has been shown to be effective in infants with NAIT in few case reports $[49,50,51]$.

Neonates of mothers with ITP: In newborns without evidence of $\mathrm{ICH} /$ or other serious bleeding, treatment with IVIG may be appropriate if platelets are $<50 \mathrm{x}$ $10^{9} / \mathrm{L}$. Newbornswithimaging evidence of ICH should be treated with IVIG \& platelet transfusion.

Kawasaki disease: It is an acute, febrile, multisystemic inflammation of the blood vessels that strike predominately newborns\& small children.IVIG has been reported to be of use neonatal Kawasaki disease [52].

Adverse effects: IVIG has been deemed safe \& is mostly well tolerated [7, 47]. Possible side effects similar to blood transfusions occur like fever, allergic reactions, hypoglycaemia, hypotension, haemolysis, fluid overload \& anaphylaxis (reported in IgA deficiency) [39]. Recently, an association with NEC has been described, but other factors in the development of NEC such as prematurity \& prenatal risk factors could not be ruled out $[36,53]$. Use of high-dose IVIG for severe isoimmunehemolytic jaundice has been associated with a higher incidence of NEC [54]. Slow infusion (at least during 4 hours) reduces the effects of hyper viscosity [53]. There is a significant increase in number of RBC transfusions required for late anaemia in those who received IVIG (RR 8.0). Unlike Exchange Transfusion, the antibody is not being washed out with IVIG use. When the effect of IVIG has worn off, the Fc sites on the surface of reticuloendothelial cells become free to bind antibody sensitised neonatal erythrocytes, thus causing haemolysis.Rare but serious side effects such as transfusion transmitted diseases, hypersensitivity, thrombosis, pulmonary emboli, cytopenia\& renal failure have been reported [30,54,55].

\section{Conclusion}

IVIG is being increasingly used in neonates for various conditions. Pending FDA approval, prompt \& judicious administration of IVIG with close monitoring for any adverse events is mandatory.

Abbreviations
AAP American Academy of Pediatrics
FDA Food \& Drug Administration
HDN Hemorrhagic Disease of the Newborn

$\begin{array}{ll}\text { ICH } & \text { Intracranial Hemorrhage } \\ \text { IVIG } & \text { Intravenous Immunoglobulin } \\ \text { LBW } & \text { Low Birth Weight } \\ \text { NAIT } & \text { Neonatal Alloimmune Thrombocytopenia } \\ & \\ \text { NEC } & \text { Necrotising Enterocolitis } \\ & \\ \text { NK } & \text { Natural Killer } \\ \text { NNT } & \text { Number Needed to Treat } \\ \text { RBC } & \text { Red Blood Cell } \\ \text { RCT } & \text { Randomised Control Trials } \\ & \\ \text { RR } & \text { Relative Risk } \\ \text { TSB } & \text { Total Serum Bilirubin } \\ \text { US } & \text { United States } \\ \text { WMD } & \text { Weighted Mean Difference }\end{array}$

\section{References}

1. Mariel Navarro, Sergio Negre, Sergio Golombek, María L. Matoses, Máximo Vento. Intravenous Immune Globulin: Clinical Applications in the Newborn. NeoReviews Jul 2010, 11 (7) e370-

378; DOI: 10.1542/neo.11-7-e370.

2. Melvan JN, Bagby GJ, Welsh DA, Nelson S, Zhang P. Neonatal sepsis and neutrophil insufficiencies. Int Rev Immunol 2010; 29:315-348.

3. Bayry J, Misra N, Latry V, et al. Mechanisms of action of intravenous immunoglobulin in autoimmune \& inflammatory disease. Trans ClinBiol2003 Jun; 10(3):165-9.

4. Mohan PV, Tarnow-Mordi W, Stenson B, Brocklehurst P, Haque K, Cavendish V, Cust A. Can polyclonal IVIG limit cytokine mediated cerebral damage and chronic lung disease in preterm infants? Arch Dis Child Fetal Neonatal Ed 2004; 89:F5F8 doi:10.1136/fn.89.1.F5.

5. Michael D. Weiss, David J. Burchfield. Adjunct Therapies to Bacterial Sepsis in the Neonate. NAINR. 2004; 4(1).

6. Nimmerjahn F, Ravetch JV. Anti-inflammatory actions of intravenous immunoglobulin.Annu Rev Immunol. 2008; 26:513-33. doi: 10.1146/annurev.immunol.26.021607.090232. 
7. Ergaz Z, Gross D, Bar-Oz B, Peleg O, Arad I. Carboxyhemoglobin levels in neonatal immune hemolytic jaundice treated with intravenous gammaglobulin. Vox Sang. 1995; 69(2):95-99. DOI: 10.1111/j.1423-0410.1995.tb01676.x

8. Shaw CK, Thapalial A, Shaw P, Malla K. Intravenous immunoglobulins and haematopoietic growth factors in the prevention and treatment of neonatal sepsis: ground reality or glorified myths? Int $\mathbf{J}$ ClinPract. 2007 Mar; 61(3):482-7.

9. Fujiwara T, Taniuchi S, Hattori K, Kobayashi T, Kinoshita Y, Kobayashi Y.Effect of immunoglobulin therapy on phagocytosis by polymorphonuclear leucocytes in whole blood of neonates. ClinExpImmunol 1997, 107(3):435-9.

10. Van den Berg JP, Westerbeek EA, van der Klis F M., Berbers GA., van ElburgRM.Transplacental transport of IgG antibodies to preterm infants: areview of the literature. Early Hum Dev. 2011 Feb; 87(2):6772. doi: 10.1016/j.earlhumdev.2010.11.003. Epub 2010 Nov 30.

11. Levy O. Innate immunity of the newborn: basic mechanisms and clinical correlates. Nat Rev Immunol. 2007 May; 7(5):379-90.

12. Chirico G, Rondini G. Plebani A et al. IVIG therapy for prophylaxis of infection in high risk neonates.J. Pediatri. 1987; 110:437 - 42 .

13. Conway SP, Gillies DR, Docherty A. Neonatal infection in premature infants and use of human immunoglobulin. Arch Dis Child. 1987 Dec; 62(12):1252-6

14. Jenson HB, Pollock BH: Meta-analyses of the effectiveness of intravenous immune globulin for prevention and treatment of neonatal sepsis. Pediatrics 1997, Feb99 (2):E2.

15. Ohlsson A, Lacy J. Intravenous immunoglobulin for preventing infection in preterm and/or low birth weight infants. Cochrane Database Syst Rev 2004;1:CD000361-CD000361.

16. Christenson KK, Christenson $\mathrm{P}$, Bucher HV, et al. IV administration of human $\operatorname{IgG}$ to newbornInfants.Changes in serum antibody levels to group B streptococci Eur. J. Pediatr.1984;143:123-127.
17. Kinney J, Mundorf L, Gleason C et al. Efficacy and Pharmacokinetics of IVIG admn to high riskneonates. AJOC 1991;145:1233-38.

18. FanaroffAA. KoronesSB, Wright LL et al. A controlled trial of IVIG to reduced nosocomial infection in VLBW infant. $\mathrm{N}$ Engl J Med. 1994 Apr 21;330 (16):1107-13

19. Magay JF, Oury CB, Brautt D, et al. IVIG therapy for prevention of infection in high risk premature infants - Reports of a multicenter double blind study. Paediatrics 1991; 88: 437-42.

20. Brocklehurst P, Farrell B, King A, Juszczak E, Darlow B, Haque K, Salt A, Stenson B, Tarnow-Mordi W. Treatment of neonatal sepsis with intravenous immune globulin. N Engl J Med. 2011 Sep 29;365(13):1201-11. doi: 10.1056/NEJMoa1100441.

21. Haque KN, Zaidi MH, Haque SK, Bahakim H. Intravenous immunoglobulin for prevention of sepsis in preterm and low birth weight infants. Am J Dis Child. 1988 Dec; 142(12):1293-6.

22. El-Nawawy A, El-Kinany H, Hamdy El-Sayed M, Boshra N. Intravenous polyclonal immunoglobulin administration to sepsis syndrome patients: a prospective study in a pediatric intensive care unit. $\mathrm{J}$ Trop Pediatr. 2005 Oct; 51(5):271-8. Epub 2005 May 25.

23. Ohlsson A, Lacy J. Intravenous immunoglobulin for suspected or subsequently proven infection in neonates. Cochrane Database Syst Rev 2010;3: CD001239-CD001239.

24. Alejandria MM, Lansang MA, Dans LF, Mantaring JBV: Intravenous immunoglobulin for treating sepsis and septic shock.Cochrane Database Syst Rev. 2013 Sep 16; 9:CD001090. doi: 10.1002/14651858.CD001090.pub2.

25. Weisman LE, Stoll B, Kueser T et al. Intravenous immunoglobulin therapy of neonatal sepsis. J Pediatr $1992 ; 121: 434-43$.

26. Weisman LE, Cruess DF, Fischer GW. Standard versus hyperimmune intravenous immunoglobulin in preventing or treating neonatal bacterial infections.Clinics in Perinatology 1993; 20:211-24. 
27. Cohen S, Porter RR. Structure and biological activity of immunoglobulins.AdvImmunol. 1964; 27:287-349.

28. Norrby-Teglund A, Haque KN, Hammastrom L. Intravenous polyclonal IgM-enriched immunoglobulin therapy in sepsis: a review of clinical efficacy in relation to microbiological aetiology and severity of sepsis. JInt Med 2006; 260: 509-516.

29. Kreymann KG, deHeer G, Nierhaus A, et al. Use of polyclonal immunoglobulin as adjunctive therapy for sepsis or septic shock. Crit Care Med 01/2008; 35(12):2677-85.

DOI:

10.1097/01.CCM.0000295263.12774.97.

30. Baxley A, Akhtari M. Hematologic toxicities associated with intravenous immunoglobulin therapy. IntImmunopharmacol 2011; 11: 1663-1667.

31. R Gottstein, R W I Cooke. Systematic review of intravenous immunoglobulin in haemolytic disease of the newborn; Arch Dis Child Fetal Neonatal Ed 2003;88:F6-F10 doi:10.1136/fn.88.1.F6.

32. Haque KN, Remo C, Bahakim H. Comparison of two types of intravenous immunoglobulins in the treatment of neonatal sepsis. ClinExpImmunol. 1995 Aug; 101(2): 328-333.

33. Haque KN, Zaidi MH, Bahakim H. IgM-Enriched intravenous immunoglobulin therapy in neonatal sepsis. Am J Dis Child. 1988 Dec;142(12):1293-6.

34. Maisel JM. Neonatal jaundice.Pediatr Rev. 2006;27(12):443-454.

35. Hara T, Mizuno Y, Kawano M, Ueki Y, Ueda K. Treatment of immune hemolytic anaemia with gammaglobulin. J Pediatr. 1987;110(5):817-818.

36. Corvaglia L, Legnani E, Galletti S, Arcuri S, Aceti A, Faldella G. Intravenous immunoglobulin to treat neonatal alloimmune haemolytic disease. J MaternFetal Neonatal Med. 2012 Dec;25(12):2782-5. doi: 10.3109/14767058.2012.718387. Epub 2012 Aug 27.

37. Charles Ahlfors, Daniel Batton, Thomas Bojko, et al., Management of hyperbilirubinemia in the newborn infant 35 or more weeks of gestation. Pediatrics. 2004 Jul;114(1):297-316.
38. Alpay F, Sarici SU, Okutan V, Erdem G, Ozcan O, Gokcay E. High-dose intravenous immunoglobulin therapy in neonatal immune hemolyticjaundice.ActaPaediatr. 1999 Feb;88(2):216-9.

39. Alcock GS, Liley H. Immunoglobulin infusion for isoimmune haemolytic jaundice in neonates. Cochrane Database Syst Rev. 2002;(3):CD003313.

40. Voto LS, Sexer H, FerreiroTavosnanska J, Orti J, Mathet ER, Margulies M, Margulies M. Neonatal administration of high-dose intravenous immunoglobulin in rhesus hemolytic disease. J Perinat Med. 1995; 23(6):443-51.

41. Rubo J, Albrecht K, Lasch $P$ et al. High-dose intravenous immune globulin therapy for hyperbilirubinemia caused by $\mathrm{Rh}$ hemolytic disease. $\mathrm{J}$ Pediatr. 1992; 121:93-97.

42. Dagoglu T, Ovali F, Samaci N, Bengisu E. Highdose intravenous immunoglobulin therapy for rhesus haemolytic disease. J Int Med Res. 1995 Jul-Aug; 23(4):264-71.

43. Tanyer G, Siklar Z, Dallar Y, et al. Multiple dose IVIG treatment in neonatal immune hemolytic jaundice. Trop Pediatr 2001;47:50-3.

44. NHS. Clinical guidelines for immunoglobulin use.2nd edn. London: Department of Health, June 2008.

45. G Girish, D Chawla, R Agarwal, V K Paul, A K Deorari. Efficacy of Two Dose Regimes of Intravenous Immunoglobulin in Rh Hemolytic Disease of Newborn - A Randomized Controlled Trial. Indian Pediatrics; Vol 45;August 17, 2008; 45:653-659.

46. Miqdad AM, Abdelbasit OB, Shaheed MM, Seidahmed MZ, Abomelha AM, Arcala OP. IVIG therapy for significant hyperbilirubinemia in $\mathrm{ABO}$ hemolytic disease of the newborn. J MaternFetal Neonatal Med. 2004 Sep;16(3):163-6.

47. ArvindShenoi, N. KarthikNagesh, P.P. Maiya, SwarnaRekhaBhat, S.D. SubbaRao. Multicenter randomized placebo controlled trial of therapy with intravenous immunoglobulin in decreasing mortality due to neonatal sepsis; Indian Pediatrics 1999; 36: 1113-1118. 
48. Ouwehand WH, Smith G, Ranasinghe E. Management of severe alloimmune thrombocytopenia in the newborn. Arch Dis Child Fetal Neonatal Ed. 2000 May; 82(3): F173-F175. DOI: 10.1136/fn.82.3.F173

49. Suarez CR, Anderson C. High-dose intravenous gammaglobulin (IVIG) in neonatal immune thromboctyopenia. Am J Hematol. 1987 Nov; 26(3):247-53.

50.BallinA, Andrew M, Ling E, Perlman M, Blanchette V. High-dose intravenous gammaglobulin therapy for neonatal autoimmune thrombocytopenia. J Pediatr 1988;112: 789-792.

51. Linder N, Shapiro SC, Moser AM, Roitman J, Engelhard D. Treatment of neonatal immune thrombocytopenia with high dose intravenous gglobulin. DevPharmacolTher 1990; 14: 205-208.
52. Stanley TV, Grimwood K. Classical Kawasaki disease in a neonate. Arch Dis Child Fetal Neonatal Ed. 2002 Mar;86(2):F135-6.

53. Figueras-Aloy J, Rodriguez-Miguelez JM, IriondoSanz M, Salvia-Roiges MD, Botet-Mussons F, Carbonell- Estrany X. Intravenous immunoglobulin and necrotizing enterocolitis in newborns with haemolytic disease. Pediatrics. 2010 Jan;125(1):139-44. doi: 10.1542/peds.2009-0676. Epub 2009 Nov 30.

54. Walsh S, Molloy EJ. Towards evidence based medicine for paediatricians. Is intravenous immunoglobulin superior to exchange transfusion in the management of hyperbilirubinaemia in term neonates? Arch Dis Child. 2009;94:739-741.

55. Kumar A, Teuber SS, Gershwin ME. Intravenous immunoglobulin: striving for appropriate use. Int Arch Allergy Immunol 2006;140:185-198 (DOI:10.1159/000093204).

\section{How to cite this article?}

Rabindran, Gedam DS. Intravenous Immunoglobulin in Neonates: Current Perspective. Pediatr Rev: Int J Pediatr Res 2016;3(1):63-68.doi:10.17511/ijpr.2016.101.12 